\title{
AS03-Adjuvanted H1N1 Pandemic Influenza Vaccine
}

National Cancer Institute

\section{Source}

National Cancer Institute. AS03-Adjuvanted H1N1 Pandemic Influenza Vaccine. NCI

Thesaurus. Code C88320.

A split-virus, inactivated influenza A (H1N1) vaccine containing H1N1 immunizing antigen combined with the adjuvant AS03, with potential immunostimulating activity. Upon intramuscular vaccination, AS03-adjuvanted H1N1 influenza vaccine may elicit an immune response against the $\mathrm{H} 1 \mathrm{~N} 1$ virus and the production of anti-H1N1 antibodies. ASO3 is a stabilized oil-in-water emulsion adjuvant containing DL-alpha-tocopherol, squalene and polysorbate 80 that non-specifically stimulates cell-mediated immune antigen responses. 